\title{
A DISTORÇÃO DOS CONTOS DE FADAS NA CONTEMPORANEIDADE E SUAS IMPLICAÇÕES NO DESENVOLVIMENTO DA SUBJETIVIDADE
}

DISTORTION OF FAIRY TALES IN CONTEMPORARY TIMES AND ITS IMPLICATIONS IN THE DEVELOPMENT OF SUBJECTIVITY

LA DISTORSIÓN DE LOS CUENTOS DE HADAS EN LA CONTEMPORANEIDAD Y SUS
IMPLICACIONES EN EL DESARROLLO DE LA SUBJETIVIDAD

Angela Maria Pires Caniato*

Naiara Valdelaine Balduino ${ }^{* *}$

\begin{abstract}
RESUMO
O conto de fadas pode ser um auxiliar muito pertinente no desenvolvimento infantil, principalmente no âmbito psíquico, nas questões que circundam a fantasia e a imaginação como elementos que tornam possível a constituição do pensamento. Porém, na Contemporaneidade, o que tem sido destacado sobre os contos de fadas não é a transmissão pela oralidade ou por leitura das histórias que implicam a relação com o outro, tampouco sua contribuição para a significação do mundo por parte da criança. O que se mostra é o atravessamento da indústria cultural na transmissão dos contos de fadas e algumas distorções na estrutura simbólica desses contos, o que tem corrompido seu caráter esclarecedor e inibido a capacidade da criança de fantasiar e simbolizar a vida. Relacionado ao tema, este trabalho é resultado de uma pesquisa bibliográfica sobre a obra de Bettelheim sobre os contos de fadas. Seu objetivo é analisar, com base num filme contemporâneo, as adaptações e as distorções dos contos na contemporaneidade bem como suas implicações no desenvolvimento da subjetividade.
\end{abstract}

Palavras-chave: Contos de Fadas. Fantasia. Indústria cultural. Criança/ infantil. Subjetividade.

\section{ABSTRACT}

Fairy Tales can be a very relevant aid in child development, mainly in the mental realm, in the issues related to fantasy and imagination as elements that make feasible the constitution of thinking. However, at

Texto recebido em 22 de março de 2016 e aprovado para publicação em 14 de setembro de 2016

Professora doutora no Programa de Pós-Graduação em Psicologia, linha de pesquisa Epistemologia e Práticas Sociais, da Universidade Estadual de Maringá-PR (UEM). Endereço: Rua Joaquim Nabuco, 1496 - Zona 4, Maringá-PR, Brasil. CEP: 87014-100.E-mail: angelacaniato@gmail.com.

${ }^{*}$ Mestranda em Psicologia pela UEM. Endereço: Rua São João, 139, ap. 5 - Zona 7, Maringá-PR, Brasil. CEP: 87030-200. E-mail: naiara-101@hotmail.com. 
contemporaneous times, what is being highlighted about fairy tales is not the oral communication or the story-reading relationship, which implies the relationship with another person, not even the contribution of the tales to the child's signification of the world. What is unveiled is the interference of the cultural Industry in the communication of fairy tales and some distortions in the symbolic structure of the tales which has been corrupting its enlightening skill and inhibiting the child's ability to fantasize and symbolize life. Nonetheless, this work comes out of a bibliographical research on Bettelheim's work about fairy tales. The main objective is to analyze, based on a contemporaneous movie, the current adaptations and distortions of the tales as well as its implications in the development of subjectivity.

Keywords: Fairy tales. Fantasy. Cultural industry. Child/Infant. Subjectivity.

\section{RESUMEN}

El cuento de hadas puede ser un ayudante fundamental en el desarrollo infantil, principalmente en el ámbito psíquico, en las cuestiones que circundan la fantasía y la imaginación como posibilitadoras de la constitución del pensamiento. Pero, lo que es retratado en la contemporaneidad sobre los cuentos de hadas, no es su transmisión oral o por lectura de estas historias implicadas en la relación con el otro y ni tampoco ha ayudado el niño a significar el mundo. Lo que existe es el cruzamiento de la Industria Cultural en la transmisión de los cuentos de hadas y algunas distorsiones en la estructura simbólica de los cuentos, corrompiendo su carácter esclarecedor e inhibiendo la capacidad del niño de fantasear y simbolizar la vida. Este trabajo constituye, por lo tanto, una investigación bibliográfica de la obra de Bettelheim sobre los cuentos de hadas, cuyo objetivo es analizar, a partir de una película contemporánea, las adaptaciones y distorsiones de los cuentos en la contemporaneidad y sus implicaciones en el desarrollo de la subjetividad.

Palabras clave: Cuentos de Hadas. Fantasía. Industria cultural. Niño/ Infantil. Subjetividad.

\section{INTRODUÇÃO}

E

ste trabalho tem como objetivos estudar detalhadamente a obra de Bettelheim (2012), intitulada $A$ psicanálise dos contos de fadas, e compreender as distorções dos contos na Contemporaneidade, as quais incidem na construção das subjetividades. Acompanhando essas transformações, realizamos uma revisão histórica do conto de fadas, desde sua origem céltica (datada no século II a.C.) até sua produção e transmissão na Contemporaneidade. 
A compreensão da subjetividade será intermediada pelos estudos de Melaine Klein, tendo em vista especialmente a relevância que a autora dá ao processo da fantasia inconsciente na constituição egoica da criança e na estruturação de sua subjetividade. Será particularizada a importância desse processo psíquico, pois a apreensão do simbólico dos contos de fadas somente é possível se nos valemos de nosso simbólico inconsciente, isto é, de nossas fantasias. Por outro lado, a mediação do existir e do "falar" dos personagens dessas histórias facilita a expressão da fantasia infantil, assim como a elaboração dos acontecimentos fantásticos e reais dos personagens dessas histórias, as quais se aproximam dos acontecimentos diários vividos pela criança.

Para o próprio Bettelheim (2012), os contos de fadas traduzem/permitem a descoberta de respostas para os dilemas cotidianos do ser humano, isto é, tanto suas narrativas quanto suas místicas expõem/fornecem respostas às indagações existenciais dos indivíduos, seja em relação à constituição do mundo, seja em relação ao modo como eles se relacionam e experimentam esse mundo.

Com tal premissa e com base na referida revisão histórica da forma literária em questão, buscamos abordar a potencialidade dos contos de fadas no desenvolvimento da vida psíquica dos indivíduos. Constatamos que, na atualidade, os contos de fadas foram apropriados pela indústria cultural, sendo utilizados na produção, transmissão e manutenção de ideologias para o consumo e a massificação. Se não bastasse essa apropriação deformante, ou melhor, mesmo pela ação dessa penetrante violência simbólica, os contos de fadas vêm perdendo seu caráter esclarecedor. Certamente pior que essa destruição é a tendência dos atuais contos de fada de encobrir/capturar, com suas artimanhas sedutoras, o simbólico da criança, enfraquecendo o desenvolvimento de sua capacidade de fantasiar e, consequentemente, de situar-se emocional e racionalmente diante do real, bem como de se apropriar gradativamente de sua própria identidade.

O viver torna-se mais sofrido para essas crianças, pois, ao ser capturadas por tais distorções, elas ainda estão vivenciando os acontecimentos cotidianos por meio de uma estrutura egoica primitiva, sem poder contar com o desenvolvimento de outros recursos simbólicos para se desvencilhar da comunicação mentirosa da indústria cultural.

A ideologia da indústria cultural, advinda do meio externo, penetra na subjetividade pelas vias senso-perspectivas e, mesmo sem ser decodificada, carrega a sedução libidinizada de seus apelos artificiais para o consumo. Atravessa toda a estrutura psíquica da criança e se aloja/captura seu inconsciente desejante, juntamente como a deformação das propagandas apelativas e a distorção de cenas literárias, cinematográficas e musicais padronizáveis. 
Esse "bombardeamento" difundido por meio da mídia enfraquece e até mesmo imobiliza o desenvolvimento egoico da criança, atrofiando, desde cedo, suas capacidades críticas de pensamento, imaginação, espontaneidade, memória, sensibilidade, etc. Acarreta ainda uma padronização da conduta e das formas de pensamento da criança, bem como a acomodação de seus sentidos, promovendo o desenvolvimento de uma percepção pré-esquematizada, pautada em aparências e produzida tecnicamente pela sociedade atual, que adestra as crianças a uma obediência dócil e servil (Maia, 2007).

Por fim, compararemos a versão de Perrault e dos irmãos Grimm do conto de fadas de Chapeuzinho Vermelho com a versão contemporânea de Edwards (2005), intitulada Deu a louca na Chapeuzinho (Hoodwinked), a fim de discutir e analisar alguns elementos essenciais no desenvolvimento subjetivo das crianças, os quis foram distorcidos no conto "supostamente atualizado".

\section{BREVE PANORAMA HISTÓRICO DO CONTOS DE FADA}

Segundo Schneider e Torossian (2009), embora a origem dos contos de fada seja diversa e pouco consensual entre os estudiosos de literatura, é possível afirmar que, inicialmente, sua transmissão era oral, sendo assimilada de geração em geração. Desse modo, após a apropriação da escrita, os contos de fada continuaram encantando as gerações posteriores, inclusive a sociedade contemporânea, que, aos poucos, foi atribuindo novos significados aos contos e utilizando-se de outros instrumentos para sua transmissão e manutenção.

Schneider e Torossian (2009) assinalam ainda que a literatura, "embora não seja unânime, aponta para a origem céltica (século II a.C.) dos contos de fadas" (p. 134), sendo possível identificar registros de histórias semelhantes aos contos nos escritos de Platão, Apuleio, filósofo do século 2 d.C., e também nos papiros dos irmãos Anúbis e Bata, no Egito.

Ferreira (1991) afirma que os povos da Idade Antiga admitiam o universo fantástico presente nos contos de fadas, uma vez que compreendiam que estes eram carregados de significados simbólicos e de metáforas que entrelaçavam o imaginário humano. É importante salientar que os contos de fadas "não eram destinados ao universo das crianças, uma vez que as histórias eram recheadas de cenas de adultério, canibalismo, incesto, mortes hediondas e outros componentes do imaginário dos adultos" (Schneider \& Torossian, 2009, p. 134). Souza (2005) descreve os contos como histórias que "Falavam do destino do homem, de suas provas e tribulações, de seus medos e esperanças, de suas relações com seu próximo e com o sobrenatural" (p. 214). 
Nesse ponto, conforme Schneider e Torossian (2009), destacamos que, antes mesmo de terem um registro escrito, como se tem hoje, os contos de fadas tinham por função a formação cultural e espiritual dos povos da Antiguidade. Além disso, os contos eram frequentemente narrados "Em campos de lavouras, reuniões sociais, nas salas de fiar, casas de chá, nas aldeias ou nos demais espaços em que os adultos se reuniam" (Schneider \& Torossian, 2009, p. 134).

No entanto os contos, que, em sua origem, eram destinados aos adultos, passaram a sofrer "Adaptações no sentido de contemplarem as necessidades das crianças, bem como de sua vida imaginária" (Schneider \& Torossian, 2009, p. 134). Os contos se configuravam em recursos fascinantes à fantasia infantil, "narrados pelas amas, governantas e, ou, pelas "cuidadoras" das crianças, que se incumbiam de contar e perpetuar histórias de origem popular, construídas com base na cultura do povo" (Schneider \& Torossian, 2009, p. 134-135).

As autoras destacam também que o modo como os contos são conhecidos na atualidade deve-se à sua origem europeia, datada do fim do século XVII e o XVIII, especialmente na França e na Alemanha (Schneider \& Torossian, 2009 , p. 135). O período histórico no qual se configurava concomitantemente a transmissão dos contos na Europa pode ser delimitado entre o momento da Contrarreforma católica e o da Segunda Revolução Industrial, que detinha o monopólio econômico da época.

Em razão desse contexto, os contos transmitidos foram "permeados pela 'moral vitoriana’ de uma sociedade repressiva quanto às questões sexuais”, na qual não se consideravam ainda "os conceitos de infância e de educação" (Schneider \& Torossian, 2009, p. 135). Só mais tarde, com a passagem da oralidade para o texto escrito e com a ascensão da burguesia, já no século XVIII, é que se passou a ter noção de família nuclear e a valorizar a infância.

Perrault, um dos precursores na coleta das narrativas populares, passou a registrar "As histórias com base em narraçôes populares, passando a adaptá-las e floreá-las conforme a necessidade da corte francesa da época" (Schneider, \& Torossian, 2009, p. 135). Além disso, censurou "detalhes da cultura pagã e da sexualidade humana” (p. 135).

Assim, segundo Schneider e Torossian (2009), os contos de Perrault, até mesmo em suas "versões infantis, são recheados de uma mensagem moral explícita, normalmente colocada em apêndices sob a forma de versos" (p. 135). A finalidade, descrita por Perrault, seria:

Servir de orientação e de ensinamento aos que a ouvissem. Apesar de escrever contos de fadas, em suas histórias, as fadas são personagens pouco presentes. Perrault preferiu introduzir 
figuras humildes, como lenhadores, serviçais, aldeões, damas e cavaleiros. Outro aspecto relevante de seus contos mostra-se na escolha em retratar as lindas paisagens francesas, suas campinas, a atmosfera desses lugares (Schneider \& Torossian, 2009, pp. 135-136).

As autoras afirmam ainda que um movimento romântico instaurado na época de Perrault "Trouxe aos contos um sentido mais humanitário" (Góes, 1991 apud Schneider \& Torossian, 2009, p. 136). Esse movimento teria substituído a violência presente nos contos de Perrault por histórias que preconizassem a solidariedade e o amor pressupostos pelo humanismo. Os irmãos Grimm destacaram-se nesse tipo de escrita fundamentada no humanismo crescente na época.

Por fim, o que se vê atualmente são autores como Cory Edwards, Todd Edwards e Tony Leech, os quais retomaram as histórias escritas por Perrault e pelos irmãos Grimm. Esses autores mantiveram alguns de seus personagens, como Chapeuzinho Vermelho, o Lobo e a Vovozinha, acrescentaram novos, como o Coelhinho, atribuíram novas características à personalidade dos personagens e, por fim, elaboraram um novo enredo. Essa versão foi lançada em 2005 com o filme animado Deu a louca na Chapeuzinho (Edwards, 2005), não só para as crianças, mas para toda a família. Contudo muitas críticas recaíram sobre essa nova trama. Cabe-nos discuti-las e analisá-las, construindo um posicionamento mais crítico e contextualizado acerca das questôes e, ou, das distorções contidas no filme, já que estas implicam diretamente sobre o desenvolvimento infantil contemporâneo.

\section{FANTASIA, O DESENVOLVIMENTO PSÍQUICO DA CRIANÇA E OS CONTOS DE FADAS}

O conceito de fantasia passou a ser objeto de estudo na psicanálise a partir do trabalho de Freud com pacientes histéricos. $\mathrm{O}$ estudo desses pacientes tornou possível que o psicanalista abandonasse a teoria da vivência de um trauma sexual como causa da histeria e passasse a dar ênfase à vida fantasística como um fator etiológico para essa enfermidade (Mezan, 2002).

Inicialmente, com base nos relatos dos pacientes histéricos, Freud e Breuer concluíram que, na origem dos sintomas histéricos, estariam cenas traumáticas de cunho sexual vivenciadas na infância. Essas cenas, por não terem recebido significação quando ocorridas, teriam permanecido como pontos de fixação e excluídas da consciência (Freud, 1897/1969) ${ }^{1}$. Inconscientes, essas cenas traumáticas seriam compulsivamente repetidas por meio dos sintomas histéricos

\footnotetext{
1 A primeira data indica o ano de publicação da obra, e a segunda, a edição consultada pelo autor, a qual somente será pontuada na primeira citação da obra no texto. Nas seguintes, será registrada apenas a data de publicação original.
} 
(Freud, 1897). Contudo, em 1897, Freud escreveu uma carta a Fliess, dizendo que já não acreditava nos relatos dos pacientes como realidade de fatos ocorridos e sim como realidade psíquica (Freud, 1897).

Freud (1897) apontava ainda que, sem a finalidade de mentir, os pacientes histéricos, ao se colocar como vítimas, estariam se defendendo de uma excitação sexual que seria alvo de suas censuras. Além disso, tais fantasias de sedução representariam o desejo inconsciente desses pacientes (Lourenço, \& Padovani, 2013). Do mesmo modo, os ataques histéricos não passariam de realizações de desejos, assim como nos sonhos.

A emergência, portanto, das fantasias como substitutas da crença na experiência sexual traumática deu novo rumo à psicanálise freudiana, uma vez que "os sintomas neuróticos foram compreendidos como representaçōes de fantasias convertidas, cujo conteúdo está relacionado a algum desejo de caráter sexual, e não a um trauma real" (Oliveira, 2008, p. 18).

Melaine Klein utilizou essas importantes contribuições de Freud para avançar na definição do conceito de fantasia: passou a compreendê-lo como "o conteúdo primário dos processos mentais inconscientes” (Isaacs, 1962, p. 574). Mesmo que Freud não tenha expressado qualquer opinião sobre essa definição, a formulação de Klein estaria de acordo com suas contribuições, conforme a seguinte citação:

Freud havia dito que "toda etapa consciente tem um inconsciente preliminar" (1932). Todos os processos mentais se originam no inconsciente e só mediante certas condições se fazem conscientes. Surgem diretamente da necessidade instintiva ou em resposta a estímulos externos que atuam sobre impulsos instintivos (Isaacs, 1962, p. 574).

Klein (1962), citada por Oliveira (2008), revelou ainda que as fantasias vão se sofisticando e se manifestam por toda a vida do indivíduo, isto é, o psiquismo do adulto é constituído a partir "das fantasias inconscientes, desde os primeiros dias de vida” (p. 25), as quais, continuando atuantes, transitam pelas diferentes estruturas do psiquismo. Acerca disso, Riviere (1986b), citado por Oliveira (2008), aponta: "A vida de fantasia do indivíduo pode ser entendida como 'a forma como suas sensações e percepções reais, internas e externas, são interpretadas e representadas para ele próprio, em sua mente, sob a influência do princípio de prazer-dor"” (p. 25).

Em muitas situações do cotidiano, "A vida de fantasia nunca é apenas fantasia, mas sim uma mistura das realidades externa e interna" (Oliveira, 2008, p. 25), de tal maneira que as fantasias "fazem[çam] parte do mundo imaginário - [do faz de conta] -, [mas] para a criança são sentidas como se realmente estivessem ocorrendo" (Oliveira, 2008, p. 31). 
As fantasias primitivas expressas na tenra infância são "processos altamente desconexos, instáveis e contraditórios" (Oliveira, 2008, p. 31). Qualquer estímulo sentido pela criança é um potencial aliciador de fantasias, tanto o agressivo (que acarreta fantasias agressivas) quanto o prazeroso (que, por sua vez, desencadeia fantasias calcadas no prazer).

Para Isaacs (1962), a fantasia primitiva caracteriza-se pela representação dos impulsos e sentimentos, e pela expressão de "desejos, mágoas, ressentimentos, amores, angústias, etc.” (Oliveira, 2008, p. 32), os quais, agregados à energia libidinal, depositam-se em alguma parte do corpo, tornando-a erógena ou atacando-a. Um exemplo desse deslocamento é o de um bebê que, privado de sua mãe, deseja seu seio, mas, sem chances de obtê-lo, fantasia que está mamando quando chupa o dedo ou um objeto qualquer. Nos primeiros meses de vida, a criança age essencialmente em consonância com suas fantasias inconscientes, as quais "Determinam toda a vida da criança neste período" (Oliveira 2008, p. 32).

A compreensão da criança e sua orientação na vida real está, então, apenas começando, ou seja, "O bebê é completamente dependente da mãe enquanto forma seu ego" (Oliveira 2008, p. 32). O depositário inicial das fantasias infantis é o corpo materno, pois, desde o nascimento da criança, a mãe é seu principal objeto relacional, seja de satisfação, seja de frustração. As fantasias de exploração do corpo da mãe são, portanto, essenciais à criança em seu processo de exploração/conhecimento do mundo. Reafirmando, é o funcionamento psíquico primário do bebê, no qual este opera necessariamente por meio da fantasia, que progressivamente, "através das relações objetais, cederá lugar às emoções mais complexas e aos processos cognitivos" (Oliveira, 2008, p. 32).

Para Bettelheim (2012), os contos de fadas funcionariam como uma grande ferramenta lúdica, já que, quando internalizados e expressos em suas fantasias, facilitam o processo infantil de apropriação do real assim como a compreensão das angústias e dos dilemas existenciais vivenciados pela criança. A forma e a estrutura "dos contos de fadas sugerem imagens à criança com as quais ela pode estruturar seus devaneios e com eles dar melhor direção à sua vida" (Bettelheim, 2012, p. 8) e, assim, lidar ou superar suas "decepções narcisistas, dilemas edípicos, rivalidades fraternas, ser capaz de abandonar dependências infantis; obter um sentimento de individualidade e de autovalorização e um sentido de obrigação moral" (Bettelheim, 2012, p. 8).

Bettelheim (2012) salienta ainda que a criança "necessita entender o que está se passando dentro de seu eu inconsciente" (p. 8). Essa compreensão de si mesma e a capacidade de lidar com seus conflitos interiores não se dão por meio de uma apreensão racional dos conteúdos de seu inconsciente, mas sim 
pela familiarização que ela vai adquirindo em seus "devaneios prolongados ruminando, reorganizando e fantasiando sobre elementos adequados da estória em resposta às pressões inconscientes" (Bettelheim, 2012, p. 8). É com base nisso que a criança vai conseguindo adaptar suas fantasias inconscientes aos simbólicos conscientes, ou seja, é esse processo que a capacitará para lidar com seus conteúdos:

$\mathrm{Na}$ criança ou no adulto, o inconsciente é um determinante poderoso do comportamento. Quando o inconsciente está reprimido e nega-se a entrada de seu conteúdo na consciência, a mente consciente será parcialmente sobrepujada pelos derivativos destes elementos inconscientes, ou então será forçada a manter um controle de tal forma rígido e compulsivo sobre eles que sua personalidade poderá ficar gravemente mutilada. Mas quando o material inconsciente tem, em certo grau, permissão de vir à tona e ser trabalhado na imaginação, seus danos potenciais - para nós mesmos e para os outros - ficam muito reduzidos. Algumas de suas formas podem então se colocar a serviço de propósitos positivos. Todavia, a crença prevalecente nos pais é que a criança deve ser distraída do que mais a perturba; suas ansiedades amorfas e inomináveis, suas fantasias caóticas, raivosas e mesmo violentas (Bettelheim, 2012, pp. 8-9, grifo do autor).

Bettelheim (2012) questiona o que já foi observado por outros psicanalistas: muitos pais acreditam que somente "a realidade consciente ou imagens agradáveis e otimistas deveriam ser apresentadas à criança - que ela só deveria se expor ao lado agradável das coisas" (Bettelheim, 2012, p. 9). Contudo, segundo o autor, essa visão reduzida acaba nutrindo "a mente apenas de modo unilateral e a vida real não é só agradável” (p. 9). Essa atitude causa mais estragos na evolução da criança, pois impede o desenvolvimento da capacidade de discriminar: inexiste um mundo perfeito e pleno de prazeres ilimitados, sem obstáculos frustrantes e sem dor e sofrimento. Ao contrário dos cuidados pretendidos por esses pais, essas crianças ficam mais expostas à desproteção de sua incompetência/angústia quando enfrentam situações reais de perigo e não conseguem se proteger. Sob essa precariedade de discriminação, a criança não saberá agir diante da ambivalência amorosidade/destrutividade inerente à vida subjetiva e relacional. Afinal, as maledicências integram o cotidiano da sociedade contemporânea e, embora não sejamos invulneráveis à inevitabilidade dessas condições hostis, devemos saber identificá-las, pelo menos para não sermos enganados.

Bettelheim (2012) afirma ainda que os pais contemporâneos desejam que seus filhos acreditem, de modo inconsequente, que todos os seres humanos são bons, isto é, "A cultura dominante deseja fingir, particularmente no que se refere às crianças, que o lado escuro do homem não existe, e professa a crença num aprimoramento otimista" (p. 9). Embora desconfiem que essa postura não é verdadeira, as crianças vivem essa mentira imposta por certos pais e que as 
vai fragilizando e alimentando sua permissividade para a aceitação de outros enganos bem mais perversos.

No entanto as crianças não são totalmente tolas e, mesmo sem ainda entender, vivenciam o prazer e o desprazer desde os momentos primitivos da vida: sorriem e choram. Por outro lado, as crianças "sabem que elas não são sempre boas; [. . . ] mas isso contradiz o que lhes é dito pelos pais e, portanto, faz a criança sentir-se um monstro a seus próprios olhos" (Bettelheim, 2012, p. 9).

Bettelheim (2012) retoma, então, a importância dos contos de fadas, evidenciando que as figuras neles presentes têm traços semelhantes à ambivalência dos homens, mostrando a polarização dos opostos em personagens distintos, a equivalência entre os fatores construtivos e destrutivos dos seres humanos. $\mathrm{Na}$ mente das crianças, às vezes, predomina um fator agregante e, em outras vezes, um desagregante: também nos contos de fadas, domina ora um personagem bom, ora um mau.

Essas polarizações, segundo o autor, não visam a salientar apenas que essa forma de comportamento seria correta, mas também que a criança consegue compreender mais facilmente a diferença entre os personagens. Ela não conseguiria fazer isso se os personagens fossem retratados de forma igualitária e sem as complexidades que caracterizam as pessoas reais. Só essa exposição da criança ao diferente é que lhe dará uma base para compreender as diferenças entre as pessoas e, dessa forma, no decorrer de suas identificações, ela irá construindo sua própria identidade subjetiva, fazendo opções representacionais de si mais ou menos conscientes até que, posteriormente, ela mesma possa optar sobre quem irá ser. Esse processo relacional/identitário, "Sobre o qual todo o desenvolvimento ulterior da personalidade se construirá, é facilitado pelas polarizações [que estão expressas nos personagens] nos contos de fadas" (Bettelheim, 2012, p. 9).

Para Bettelheim (2012), as escolhas infantis não se baseiam estritamente na oposição certo e errado, mas principalmente na capacidade da criança de se identificar com esse outro, capaz de atraí-la ou de lhe despertar certa antipatia. Dessa maneira, "Quanto mais simples e direto é um bom personagem, tanto mais fácil para a criança identificar-se com ele e rejeitar o outro mau" (Bettelheim (2012, p. 10). Isso porque, para o autor, a criança é capaz de se identificar com o herói não porque este seja bom, mas porque "a condição do herói lhe traz um profundo apelo positivo” (Bettelheim, 2012, p. 10).

Desse modo, encarar a vida acreditando na possibilidade de debelar os problemas e as dificuldades, ou até mesmo na probabilidade da ruína, implica um apelo desejante e investimentos afetivos diferenciadores que fortalecem a luta por si mesma. As diferentes expressões afetivas dos personagens, as quais 
aparecem nos contos de fada de forma explícita, quais sejam, amor e cuidado, cooperação consigo e com o outro, raiva/ódio pelos que são demoníacos e maltratam os demais e ataque/medo pelos que se insinuam perigosamente, etc., vão desenvolvendo na criança a diferenciação entre bom e mau, proteção e perigo e, consequentemente, fortalecendo sua sensibilidade no discernimento afetivo para o enfrentamento do cotidiano.

Porém, o que tem ocorrido na Contemporaneidade é que a criança, ainda incapaz de expressar suas angústias e sentimentos em palavras, fica restrita a dizer indiretamente aos pais que está com "medo do escuro, de algum animal, ansiedade acerca de seu corpo" (Bettelheim, 2012, p. 10), etc. Não há dúvidas de que essas situações, embora expressas com essa pobreza simbólica, criam um desconforto nos pais, pelo sofrimento que estes veem nos filhos. No entanto nem sempre os primeiros conseguem lidar com essas vivências em si mesmos e menos ainda identificar que emoções/situações o filho está expressando. Assim, a tendência passa a ser a negá-las ou, ainda, abrandar "Estes ditos medos a partir de sua própria ansiedade, acreditando que abrigará os temores infantis" (Bettelheim, 2012, p. 10).

Os contos de fadas atuais, em vez de se apresentarem como recursos simbólicos úteis aos pais e a seus filhos no alívio e elaboração dessas angústias, se limitam a versões enfeitadas, simplificadas e distorcidas que lhe abrandam o sentido e lhes roubam todo o significado mais profundo dessas histórias. É o caso dos filmes e espetáculos de tevê, nos quais os contos de fadas são transformados em diversão tola (Bettelheim, 2012).

Essa diversão é o que as crianças e as famílias mais consomem no mundo contemporâneo. Seu consumo massivo movimenta o mundo dos negócios e o grande mercado cinematográfico, os quais, por sua vez, desqualificam e degradam "o papel filosófico-existencial da cultura" (Matos, 2010, p. 25). Aquilo, portanto, que outrora fora chamado de cultura está hoje incorporado à esfera dos negócios, ou seja, a cultura passou a ser business, o que implica que o espaço para o exercício do pensamento autônomo e reflexivo tornou-se diminuto em favor do pensamento administrado e submetido à lógica do sistema econômico (Maia, 2007). Tal é o sentido essencial do conceito de indústria cultural, elaborado por Adorno e Horkheimer (Adorno, 1986) em 1947: por meio de sua ação, "A cultura é reduzida a um amplo conjunto de mercadorias culturais, nas quais resplandece o valor de troca, em detrimento do valor de uso" (Maia, 2007, p. 121).

Deslocada para o mundo da mercadoria, a criança passa, portanto, a ter dificuldade para, por exemplo, compreender as questóes éticas e morais ligadas à 
sua vida cotidiana, como a situação de roubo. Muitos contos atuais apresentam esse tema de maneira deformada e, em sua indiferenciação, tais questôes tornamse "ignoradas" pela criança, porque são internalizadas de forma banalizada. Assim, a criança vai regredindo e não desenvolve os recursos simbólicos e emocionais necessários para lidar com temas como as leis, o crime e suas consequências (a punição), entre outras questôes éticas e morais necessárias a seu desenvolvimento psicossocial. Além disso, valores como troca, respeito, solidariedade, por exemplo, são substituídos por slogans (pautados no capitalismo) do "faça você mesmo", "seja único, seja diferente", entre outras frases que, desde cedo, levam a criança a aderir a essa lógica, sem sequer pensar e ponderar as consequências dessas inversões.

A indústria cultural impõe (de maneira consciente e inconsciente) uma literatura infantil que difunde os valores da sociedade de consumo e se apropria da fantasia da criança; em consequência, efetiva-se a desvinculação da estrutura afetiva e mental do que é próprio de sua fase evolutiva. Adorno (1995), no texto Tempo livre, considera que o abandono valorativo da fantasia renunciada seria uma estratégia de adaptação extrema, pois, sem o desenvolvimento criativo (característica do poder da fantasia) e com o atrofiamento dos processos psíquicos da fantasia e imaginação, seria impossível uma real mudança de vida:

A fantasia fica tão suspeita quanto a curiosidade sexual e o anseio pelo proibido, assim como dela suspeita o espírito de uma ciência que já não é mais espírito. Quem quiser adaptarse, deve renunciar cada vez mais à fantasia. Em geral, mantida por alguma experiência da primeira infância, nem consegue desenvolvê-la. A falta de fantasia, implantada e insistentemente recomendada pela sociedade, deixa as pessoas desamparadas em seu tempo livre (Adorno, 1995, pp. 76-77).

Tais deformaçôes conceituais (violência simbólica da indústria cultural), provenientes da forma contemporânea das relações entre os indivíduos e forjadas pelo ocultamento destrutivo das "mentiras manifestas" (ideologia), fazem com que as crianças cresçam expostas à recusa de se admitirem as arbitrariedades sociais. Ao mesmo tempo, alimentam um narcisismo perverso que nega as reais limitaçôes subjetivas e a necessidade de amparo.

O pensamento crítico é construído com base na flexibilização simbólica da fantasia, a qual se incorpora às representações da consciência, produzindo interpretações coerentes do real-externo. É apenas esse processo que torna possível dissolver a rigidez das "ideias" preestabelecidas (ideologia), as quais são fixadas socialmente (indústria cultural) no psiquismo porque são internalizadas/ capturadas diretamente pelo inconsciente da destrutividade psíquica. Se os indivíduos estiverem desprovidos da flexibilidade do pensamento crítico e, 
portanto, da capacidade de interpretação consciente do perverso internalizado, acabam caindo na culpabilização autodestrutiva.

Conclui-se, portanto, que, quando os contos de fadas são capturados pela lógica do mercado, não mais propiciam às crianças os prazeres e as evoluções simbólicas sustentadas pelas fantasias e tampouco os humanizam culturalmente. Pelo contrário, atrofiam e normatizam seus desejos com a introjeção de modelos consumistas perversos, formando subjetividades condescendentes com a violência, o individualismo, o preconceito e a discriminação. Além disso, favorecem uma visão tolerante das contradições desumanas da sociedade contemporânea, levando as crianças a seguir os modelos falsos de viver em que o indivíduo é louvado por sua onipotência e onisciência, a fim de se tornar incondicionalmente "feliz".

\section{CHAPEUZINHO VERMELHO E SEU RETRATO CONTEMPORÂNEO}

Conforme Figueiredo (2007), a primeira versão escrita de Chapeuzinho Vermelho foi a de Charles Perrault, publicada em 1697, e uma das últimas é o filme de animação de Edwards (2005), intitulado Deu a louca na Chapeuzinho (Hoodwinked). Para o autor, Perrault dedicava-se a produzir diversos gêneros literários (como fábulas, contos, textos curtos em prosa, epístolas, epigramas, etc.) para o público que frequentava os salóes e a corte no século XVII. Além disso, ele se focava no aspecto didático do conto, principalmente no que dizia respeito à educação feminina. O autor afirma ainda que Perrault "se considerava o grande defensor das mulheres e, ao escrever os contos que corriam de boca em boca, em múltiplas versôes, deu-lhes uma forma definida e definitiva, pois foi assim que eles chegaram até nós" (Figueiredo, 2007, p. 29).

Após 160 anos, os irmãos Wilhelm e Jacob Grimm retomaram o conto Chapeuzinho e escreveram uma continuação para a história, retirando-lhe o aspecto cruel e imoral, a fim de direcioná-lo ao público infantil (Corso, \& Corso, 2006). A citação a seguir explicita melhor isso:

Chapeuzinho Vermelho tem duas versões: na primeira, a avó e Chapeuzinho são salvas pelos caçadores, que abrem a barriga do lobo, retirando-as vivas lá de dentro; e na segunda, uma espécie de continuação, Chapeuzinho, que aprendeu a lição, não mais ouve o lobo na floresta, seguindo o caminho certo e justo. No conto de Perrault, entretanto, o lobo devora tanto a avó quanto a Chapeuzinho e não há final feliz. Segue-se ao texto em prosa, uma Moralité em verso em que Perrault explicita o caráter sexual desta devoração, ou seja, as moças têm que ter juízo e não se deixarem seduzir pelos homens que, com sua lábia, se mostram doces e gentis, mas são na verdade verdadeiros lobos. Perrault, ao criar personagens 
frágeis e vulneráveis, que estão à espera de um príncipe encantado que venha salvá-las (Bela Adormecida, Gata Borralheira), ou que são vítimas de homens sanguinários/lobos (Barba Azul, Chapeuzinho Vermelho), cristalizou e perpetuou algumas representações da mulher no imaginário ocidental (Figueiredo, 2007, p. 29).

Partindo, portanto, das narrativas de Perrault e dos irmãos Grimm, e chegando até as histórias contadas na Contemporaneidade, observamos que tanto os aspectos eróticos, "em que a Chapeuzinho se despe para entrar na cama do lobovovozinha" (Corso, \& Corso, 2006, p. 53) quanto os aspectos canibalísticos "quando, antes de comer a menina, o lobo lhe serve a carne e o sangue da avó" (p. 53) foram sendo "suprimidos, substituídos e suavizados" (p. 53) pelos autores. Tais características são evidenciadas por Figueiredo (2007), em sua análise da versão contemporânea Deu a louca na Chapeuzinho:

Chapeuzinho não é comida pelo Lobo, a Vovó desempenha um papel dúbio, além de ser praticante de esportes radicais, o Lobo perde sua violência assim como sua virilidade, e outras personagens, como o detetive e os vilóes, não existentes no conto, são acrescentadas a fim de criar uma trama policial. A investigação é desencadeada pelo roubo de um livro de receitas, único elo aparente com a história de Chapeuzinho Vermelho, já que ela ia levar bolos para a vovozinha. Das três personagens centrais, é a Vovó que se torna protagonista, sobretudo nas cenas de esportes radicais. Avaliando a animação, a música e o enredo policial, pode-se afirmar que a comédia visa a agradar toda a família e não só as crianças, tendência que tem sido observada nos filmes infantis dos últimos tempos (Figueiredo, 2007, p. 28).

Acerca disso, Figueiredo (2007) afirma que, além do filme Deu a louca na Chapeuzinho, outras versões produzidas no século XX subvertem e, ou, desconstroem o caráter didático e moralizador do texto de Perrault: "Cada autor que reescreve a história desloca o foco da ação, privilegiando um ou outro aspecto ou colocando mais luz sobre uma ou outra personagem" (p. 30).

Com essas modificações, portanto, deixa-se de preservar o que há de essencial nesse conto, a exemplo do drama sobre a perda da inocência, da curiosidade sexual infantil, da força da figura paterna e do medo como defesa em razão das angústias infantis.

Nesse sentido, quando se trata da curiosidade sexual e da perda da inocência, percebe-se que, na versão original, Chapeuzinho está cativada por algo que ainda não é capaz de compreender, somente sentir. Há algo que a seduz e fascina. $\mathrm{Na}$ intriga, certamente, não é a beleza do Lobo e sim o desejo dele que a leva - "com a ingenuidade de quem não sabe - e ainda não suporta saber" (Corso, \& Corso, 2006, p. 53) - a se interessar pelo algo a mais que anima os adultos, o sexo. Assim, a menina acaba por representar "A transição da aparente inocência infantil para o conhecimento da existência das práticas sexuais adultas, que surgem na vida 
da criança às vezes através de uma sedução imaginada ou, em casos graves e traumáticos, vividos" (Corso, \& Corso, 2006, p. 53).

Isso demonstra que o conto Chapeuzinho Vermelho trabalha com o tema da sexualidade infantil "dentro do território do possível e necessário" (Corso, \& Corso, 2006, p. 55) das crianças pequenas, incitando-as a desvelar suas curiosidades sexuais por meio da estória, já que ainda não estão prontas para verbalizar esse dilema e tampouco para exercer sua sexualidade. Contudo, o que tem ocorrido nas versões contemporâneas é a retirada desses aspectos eróticos e canibalísticos (repressão social) que inibem a criança e a impedem de descobrir e investigar aos poucos as demandas sexuais existentes em si e nos outros. Isso é explicitado por Figueiredo (2007) ao analisar o filme Deu a louca na Chapeuzinho:

O aspecto sexual é esvaziado em proveito da trama policial e de outros aspectos da vida contemporânea, como os esportes radicais, o desejo de se tornar ator, as atividades jornalísticas. Estes autores, ao reescreverem o conto, não só aumentam um ponto, como desconstroem uma imagem de mulher frágil e indefesa e constroem imagens mais complexas e variadas (p. 30).

Outro aspecto cujo sentido foi esvaziado no filme de animação Deu a louca na Chapeuzinho é a figura do Lobo, que perde, segundo Rangel e Sendra (2012), suas características de vilão mau e perverso, ou seja, o "Lobo perde sua violência assim como sua virilidade" (p. 28), assumindo-se como um detetive que procura descobrir os vilóes dos contos de fadas. Notamos aqui o esvaziamento da figura agressiva e autoritária do Lobo, diferentemente do que se poderia pensar das versóes de Perrault e de Grimm, nas quais ele seria o representante da autoridade paterna no "sentido de colocar as coisas no seu lugar e impor as leis" (Corso, \& Corso, 2006, p. 54).

A versão contemporânea do conto de Chapeuzinho acaba por desconsiderar a importância de a criança temer o pai e ir, aos poucos, introjetando as leis e as condutas sociais que, imputadas por ele, são fundamentais na constituição da personalidade infantil. Além disso, nessa lógica, o desejo paterno, especialmente por parte da menina, torna-se irrelevante e, acima de tudo, destituído de qualquer possibilidade de simbolização (Corso, \& Corso, 2006). Contudo esse desejo é extremamente necessário para o desenvolvimento da feminilidade, principalmente quando a menina entra na adolescência. Ou seja, o lobo pode ser uma forma de a menina simbolizar o desejo paterno até ir, aos poucos, decodificando que "O lobo-pai teria de se restringir às mulheres da sua geração, sem assuntos a tratar com crianças e senhoras com idade para ser sua mãe" (Corso, \& Corso, 2006, p. 54). 
Corso e Corso (2006) afirmam também que, se a criança "não soubesse que há um lobo adulto rondando lá fora, não teria tranquilidade para ficar oculta sob o tecido, teria medo de nunca sair de lá” (p. 58), pois o terror mais primitivo da criança "é o de ser enterrado vivo nas entranhas da mãe" (Corso, \& Corso, 2006, p. 58). Destarte, segundo o autor, quem faz a criança sair de seu refúgio é o Lobo, ou seja, a maioria das crianças acaba elegendo alguma figura amedrontadora para seu uso pessoal, "conhecida pelos psicanalistas como objeto fóbico" (Corso, \& Corso, 2006, p. 58). Os objetos fóbicos encontram-se cotidianamente nos locais mais frequentados pelas crianças, já a fobia se manifesta na infância como um recurso de defesa capaz de confrontar "uma forma de medo muito mais terrível, que é a angústia: essa sensação de que algo indefinível e não localizável nos ameaça" (Corso, \& Corso, 2006, p. 58).

Para Freud (1948), o medo, bem como a ansiedade (estado afetivo que o segue), é uma manifestação do instinto de autopreservação, visto que este se caracteriza como "um aumento da atenção sensória e da tensão motora" (pp. 262-263), ou seja, como uma resposta do organismo à percepção de um perigo iminente, isto é, o medo apronta o indivíduo para a fuga ou a defesa (combate a ameaça), dependendo do contexto.

O autor verifica, assim, que "o medo é uma característica protetora do ser humano e que sua ausência poderia acarretar consequências desastrosas tanto para o indivíduo como para a nossa espécie" (Caniato \& Nascimento, 2007, p. 55). Dessa maneira, Freud (1948) compreende que a percepção iminente de um perigo e, consequentemente, a ansiedade dependem "do estado de conhecimento da pessoa e de seu senso de poder vis-à-vis com o mundo externo" (p. 262).

Dessa maneira, um indivíduo qualquer que averigue um possível sinal de perigo e esteja convicto de suas capacidades de confrontá-lo emprega "o sentimento de medo e as alterações corpóreas a ele correspondentes para defender-se ou fugir da fonte de ameaça, conforme o que lhe parecer mais apropriado na ocasião" (Caniato \& Nascimento, 2007, p. 57). Contudo se o perigo não é constatado, até mesmo ocultado e, por algum motivo, impedido de ser "vivido pelo sujeito, este permanecerá desavisado e, dessa forma, vulnerável à ameaça" (Caniato \& Nascimento, 2007, p. 57).

O que se percebe na versão contemporânea de Edwards (2005) é que a Chapeuzinho não teme mais o Lobo (representante do pai) e tampouco visa a conquistar para si a atenção dele. O que acontece, segundo Rangel e Sendra (2012), é que a doce menina, frágil e ingênua (características infantis), não se deixa mais seduzir e ser pega pelo Lobo. Chapeuzinho, nessa versão, é "esperta e sedutora” (Rangel \& Sendra, 2012, p. 30) (como o Lobo era na história original): 
ela ganha a força da onipotência, antes atribuída ao Lobo, e mais, treinada em karatê, é capaz de tomá-lo como sua vítima. Além disso, o medo, nessa versão, é ocultado sob a aparência de um coelhinho de face felpuda, rosada e de aspecto bondoso e fraternal. Dessa forma, a criança não conseguirá diferenciar o sujeito que representa perigo daquele que é dócil e fraternal, pois o papel de vilão não é mais atribuído ao Lobo e sim ao coelhinho de aparência bondosa. Essas distorções pervertem, portanto, a percepção de medo da criança, fragilizando-a e confundindo-a no reconhecimento do medo real, bem como dificultando o processo de identificação e idealização de figuras positivas importantes na estruturação egoica.

Por um lado, a criança pode acreditar que é onipotente e nada deve temer; por outro, pode ficar paralisada e exposta ao perigo imposto pelas ideologias manipuladas pela mídia e pelas propagandas típicas da indústria cultural, as quais colocam a criança em situação de "vulnerabilidade psicossocial" (Caniato \& Nascimento, 2007, p. 56). Esse contexto pode fazer com que ela se sinta cada vez mais acuada e amedrontada ante as distorçôes bruscas que acompanham seu desenvolvimento psicoafetivo e que poderão levá-la "à obediência e submissão" (Caniato \& Nascimento, 2007, p. 56) ou, ainda, dar-lhe a falsa sensação de que será capaz de dominar qualquer situação inesperada que se lhe apresente.

Assim, a indústria cultural, segundo Pinto (2010), acaba por não propiciar "prazer nem humanização (enquanto evolução cultural) incentivando uma falsa sociedade e colaborando para conservar a ordem capitalista e fazer crer que a vida desumana pode ser tolerada" (p. 11). Afinal, dessa lógica não é interessante descortinar os infortúnios sociais e suas contradições, já que se oferta um modelo de "sucesso, felicidade e lazer que é e deve ser seguido por todos" (Pinto, 2010, p. 11). Para Adorno (2008), os filmes contemporâneos, incluindo a nova versão de Chapeuzinho Vermelho, evidenciam apenas sua:

Força regressiva: seu horror otimista demonstra no conto aquilo que sempre serviu à injustiça, e deixa transparecer nos malvados bem regrados o semblante daqueles que a sociedade integral condena e cuja condenação sempre foi o sonho da socialização. [. . .] O filme, que hoje adere de modo tão inescapável nos homens que parece fazer parte deles, ao mesmo tempo está o mais distante possível da sua vocação humana, que se poderia realizar de um dia ao outro; e a apologética vive da resistência a pensar essa antinomia. [. . .] O filme logrou converter os sujeitos em funções sociais de maneira tão completa que, inteiramente capturados e incapacitados de se darem conta de qualquer conflito, eles gozam a própria desumanização como felicidade do calor humano. $\mathrm{O}$ nexo total da indústria cultural, que nada deixa de fora, é idêntico à ofuscação social total (Adorno, 2008, p. 202).

Em síntese, esses contos "atuais" que são apresentados pela indústria cinematográfica capturam os desejos mais primitivos de crianças e adultos sem 
que estes percebam e compreendam a situação real em que estão inseridos. Essa ofuscação do real permite que cada um goze de sua própria desumanização, de seus fracassos relacionais, da decadência dos princípios éticos e morais e, ao mesmo tempo, impede que os indivíduos percebam que estão fragilizados subjetivamente e adaptados aos ditames da indústria cultural e da sociedade do consumo.

\section{CONSIDERAÇÕES FINAIS}

Em síntese, os contos de fadas empregados nos dias atuais, a exemplo da versão do filme Deu a louca na Chapeuzinho, analisado neste artigo, trazem histórias padronizadas que acabam fortalecendo o individualismo, dificultando as trocas relacionais e até mesmo impedindo a internalização de representações simbólicas que enriquecem o mundo de fantasia das crianças. Além disso, dificultam que elas desenvolvam a diferenciação entre a autonomia e o respeito à alteridade. Assim, as crianças podem ficar enlaçadas em uma simbiose desestruturante ou então em situação de desamparo.

Torna-se evidente que a indústria cultural impõe (de modo consciente e inconsciente) estórias infantis que difundem os valores da sociedade de consumo e, assim, apropriando-se da fantasia da criança, efetiva a desvinculação entre a estrutura afetiva e mental e o que é próprio de seu desenvolvimento. $\mathrm{Na}$ vida cotidiana da criança, isso significa um atrofiamento de suas capacidades egoicas de simbolização, abstração, imaginação, fantasia, memória, entre outras, já que, na lógica da sociedade de consumo, tais capacidades são reduzidas a padronizações, acomodações e reproduções que eliminam a singularidade e as qualidades de cada indivíduo. Além disso, as distorçôes dos contos contemporâneos têm dificultado que a criança distinga elementos perigosos. No caso da versão analisada, o medo é ocultado sob a aparência de um coelhinho de aspecto bondoso e fraternal. Desse modo, a criança não consegue ter critérios concretos para saber o que é ou não perigoso e, portanto, não terá parâmetros para distinguir o que é saudável para si, aceitando passivamente tudo o que lhe é imposto.

Consideramos que, mesmo com esse cenário um tanto quanto pessimista e sombrio, torna-se necessário, com o apoio da escola e das famílias, retomar a função essencial dos contos de fadas, para que se possa reconhecer sua importância na vida psíquica da criança. Em vez de propiciar espaços solitários e o acesso ilimitado à mídia e a seus conteúdos excessivos e, na maioria das vezes, incompreensíveis para a criança, precisamos construir com ela espaços de troca e transmissão das estórias infantis. Assim, poderemos recuperar os valores morais e éticos dos contos e fomentar, juntamente com a criança, um pensar 
mais crítico sobre a sociedade e sobre seus conflitos internos. É na relação com o outro que a criança conseguirá obter mais recursos simbólicos para ressignificar seus dilemas infantis e se fortalecer egoicamente, bem como para caminhar rumo à humanização de si mesma. 


\section{REFERÊNCIAS}

Adorno, T. W. (1986). Indústria cultural. In T. W. Adorno. Sociologia. São Paulo: Ática.

Adorno, T. W. (1995). Tempo livre. In T. W. Adorno. Palavras e sinais: modelos críticos. (pp. 76-77). Petrópolis: Vozes.

Adorno, T. W. (2008). Minima moralia: reflexōes a partir da vida lesada. Rio de Janeiro: Azougue.

Ariès, P. (1981). História social da criança e da família. Rio de Janeiro: Livros Técnicos e Científicos.

Bettelheim, B. (2012). A psicanálise dos contos de fadas. São Paulo: Paz e Terra.

Caniato,A.M.P.\&Nascimento, M.L. (2007).Avigilânciana contemporaneidade: seus significados e implicações na subjetividade. Psicologia em Revista, 13(1), $55-57$.

Corso, D. L., \& Corso, M. (2006). Fadas no divã: psicanálise nas histórias infantis. Porto Alegre: Artmed.

Edwards, C. (Direção). (2005). Deu a louca na Chapeuzinho. [Filme de animação]. Los Angeles: Europa Filmes.

Ferreira, M. P. (1991). Contos de fada como atividade terapêutica. Jornal Brasileiro de Psiquiatria, 40(4), 160-162.

Figueiredo, E. (2007). Deu a louca na Chapeuzinho. Letras, 34, 27-38. Recuperado a partir de https://periodicos.ufsm.br/letras/article/view/11938

Freud, S. (1897). Estratos dos documentos dirigidos a Fliess: Rascunho L. In J. Salomão (Trad.), Edição standard das obras psicológicas completas de Sigmund Freud (Vol. 1, pp. 297-299). Rio de Janeiro: Imago, 1969. (Publicado originalmente em 1897).

Freud, S. (1948). La angustia. In S. Freud, Obras psicológicas completas de Sigmund Freud. (pp. 262-263). Madrid: Biblioteca Nueva.

Isaacs, S. (1962). Naturaleza y función de la fantasía. In M. Klein, Obras fundamentales em psiquiatria, psicoanalisis epsicologia: desarrollos en psicoanalisis. (pp. 80-83). Buenos Aires: Hormé. 
Lourenço, L. C. A. \& Padovani, R. C. (2013). Fantasias freudianas: aspectos centrais e possível aproximação com o conceito de esquemas de Aaron Beck. Psico-USF, 18(2), 321-328. Recuperado a partir de https://dx.doi.org/10.1590/ S1413-82712013000200015

Maia, A. F. (2007). Theodor Adorno e os conceitos de ideologia e tecnologia. In J. L. Crochik (Org.), Teoria crítica e formação do indivíduo. (pp. 115-127). São Paulo: Casa do Psicólogo.

Matos, O. C. F. (2010). Indústria cultural e imaginação estética. In J. C. Soares (Org.), Escola de Frankfurt: inquietudes da emoção. (pp. 25-33). Rio de Janeiro: EdUERJ.

Mezan, R. (2002). Interfaces da psicanálise. São Paulo: Companhia das Letras.

Oliveira, M. P. (2008). Melanie Klein e as fantasias inconscientes. (Dissertação de Mestrado). Universidade Federal de Santa Catarina, Florianópolis.

Pinto, C. V. (2010). Trabalho e educação: um debate acerca do cinema de animação nas escolas. In Anais do 7 Seminário de Saúde do Trabalhador, 5 Seminário $O$ Trabalho em Debate "Saúde Mental Relacionada ao Trabalho". Franca: Unesp. Recuperado a partir de http://www.proceedings.scielo.br/scielo.php?script=sci_ arttext\&pid=MSC0000000112010000100031\&lng=en\&nrm=abn

Rangel, I. R. \& G. Sendra, A. P. (2012). Chapeuzinho Vermelho: de Perrault ao ciberespaço. (Dissertação de Mestrado). Universidade Estadual do NorteFluminense Darcy Ribeiro, Campos dos Goytacazes.

Schneider, R. E. F. \& Torossian, S. D. (2009, agosto). Contos de fadas: de sua origem à clínica contemporânea. Psicologia em Revista, 15(2), 134-136.

Souza, M. T. C. C. (2005). Valorizações afetivas nas representaçôes de contos de fadas: um olhar piagetiano. Boletim de Psicologia, 55(123), 1-22. 